\title{
Adaptive Distance Learning Programs Based On Feedback Evaluation And Continuous Progress Assessments
}

\author{
Lubomir Bojilov, University of California Santa Barbara, USA \\ Jivka Bojilova, University of California Santa Barbara, USA \\ Desislava Kachlakeva, DDK Consulting Services, Ltd., USA and Bulgaria \\ Damian Kachlakev, California Polytechnic State University, USA
}

\begin{abstract}
This paper presents a new technological approach to the online education that will allow for individualized and personalized adaptation of the curriculum. Based on the integration with and correlation of the results of student's self-assessment, their multi-rater 360-degree feedback evaluation and the continuous study progress checks, a modern information system can automatically determine, generate, and continuously adjust the level, the instructional flow, and the specifics of the course content. The authors present their innovative idea for integrated webbased educational system and methodology, which is currently being designed. The system will target the demands for professional development and improvement in customer service and relations with customers in the travel and tourism industries and the public administration.
\end{abstract}

Keywords: Online, Education, Assessment, 360-Degree, Tourism, System

\section{INTRODUCTION}

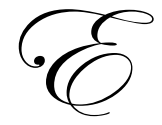

very individual possess different level of intrinsic and acquired skills, knowledge, experience, and behaviors. As a result, every person has distinctive necessities for education and areas for further development. In most cases, the standard methods for providing instruction and learning programs do not take into any consideration these modification factors and are not able to deliver the individualized learning content and methods that reflect the student's needs, potentials, and ongoing progress.

In today's increasingly complex and competitive business climate, to achieve and sustain success the companies and the public organizations have no choice but to operate with optimal efficiency and responsiveness to customers' needs and desires. As part of this ongoing effort, the companies must continually inspire, encourage, and improve their employees' on-the-job performance. According to Dr. Shoikova (2009), "The world competitive economy places new demands on individual workers and organisations: new activities, new technologies, new markets, changing jobs, etc. Individuals are permanently triggered to further develop their competences." (p. 313)

Most of the currently existing types of conventional distance trainings, such as e-learning programs and performance evaluation processes, are inconsistent, isolated, and often limited only to providing one-size-fits-all curriculum that does not help to address the individual capabilities and requirements for professional development. At the same time, "Despite the potential for 360-degree feedback to motivate behavioral change, little information exists on how to best communicate feedback to the recipient to ensure that it is accepted, internalized, and used to enhance performance." (Lobsenz, et al, 2004, p.5). Therefore, a new holistic, nimble and adaptive educational approach for individualized learning program that is based on the specifics of an all-inclusive competency determination seems fundamental to meet today's' and tomorrow's needs for professional and educational advancement. 


\section{PERSONALIZED DISTANCE EDUCATION}

The proposed solution to the abovementioned educational and professional development needs is to create a "Personalized Distance Education", which is based on a methodology to correlate and integrate the four key components of individual needs determination and adaptive learning, i.e.: 1) self-assessment, 2) multi-rater feedback, 3) ongoing progress evaluation, and 4) instructional content and experience. Such logical and physical interrelation and incorporation can be achieved by utilizing contemporary mobile and internet-based information technologies and applying scientific approaches to develop new methodology, competence framework, and to design a new personalized distance education competence-based system.

\section{Self-assessment}

The online self-assessment component is the first important factor of the holistic modeling of the bespoke pattern for the personalized education process. The questionnaire is based on and covers the key subjects of the program of study and additionally links questions to competency items. The type of information targeted is: knowledge (familiarity with job, industry, the organization), skills (task proficiency), and behaviors (patterns in relating to the environment; e.g., friendliness, energy, optimism).

The online self-assessment provides the first set of quantifiable data on self-perceived soft skills and competencies that later the system will factor to determine the study level, the flow of instructions, materials, exercises, and quizzes.

\section{Multi-rater 360-degree feedback}

The second important step in the solution is the administration of a multi-rater 360-degree feedback, an Internet based feedback process for collecting and analyzing data on people's demonstrated behaviors and competencies. During this stage of data gathering, based on mirror questionnaire of the self-assessment, the students can invite and receive feedback from the full circle of perspectives - managers, peers, direct reports, and stakeholders (such as internal or external customers). The 360-degree feedback has long been recognized as an indepth, impactful, and accurate way of uncovering blind spots and assessing person's perceived performance, habits, strengths and development needs (weaknesses), all of which can be used to identify training needs.

This powerful tool for gaining insight into strengths and weaknesses provides the second set of quantifiable data that the system can immediately analyze and utilize in determining the individualized program of study.

\section{Ongoing progress evaluation}

The specific results on the chapter quizzes, the answers to blitz questions, the speed of covering instruction materials, and even the topic selection behavior can be used to compile a set of data which will determine the ongoing automatic adaptation of the program of study.

The ongoing progress evaluation background process provides a real time continuing flow of information that is utilized by the system's Decisions Engine, which applies fuzzy logic, Bayesian probability and proprietary algorithms to define and modify accordingly the course content.

\section{Integrating and generating the personalized instructional content and experience}

"While online programs are touted as a convenient alternative to traditional instruction, potential students are beginning to judge programs on quality, cost, accreditation, and the technology being used"(Carnevale, 2006, p.A35).

The online education allows for rich multimedia and interactive content. In addition, this technology-based environment is also supporting the application of various scientific and statistical methods in generating a personalized education programs based on the holistic information gathered through self-assessment, 360-degree feedback, and progress tracking of the student. 
"The concept of competence can bridge the world of education, training, knowledge management, human resource management and informal learning" (Shoikova, 2009, p. 316). From the consolidated feedback gap analysis between how a student perceives her/himself and how others perceive them, the system identifies strengths to build upon, areas of weaknesses to be improved, and potential disconnects, like "blind spots" (high self ratings, low others' ratings) and "untested strengths" (low self ratings, high others' ratings).

In addition, to express the statistical representations of the respondent's agreement, the system calculates the standard deviation and frequency tables. The standard deviation describes variability in ratings distributions and can be thought of as a rough measure of the average amount by which ratings deviate from the mean. Because the standard deviation does not show the distribution of ratings, the system calculates frequency tables, which represent the number of raters assigning a rating to a specific behavior.

Finally, the provided individuals' feedback is benchmarked against other feedback recipients through the use of norms, which express how they are performing in relation to others.

The entire program of study is aggregated into a database persisted superset, with each of its elements and characteristics described with discipline-specific or industry-specific metadata catalog. Such structured metadata approach helps solving the problem of integrating and utilizing complex, heterogeneous data, by representing "'arbitrary' data structures through explicit documentation in a standardized, discipline-specific vocabulary" (Jones, 2001, p.68). In our case study, the industry will be travel and tourism with specialization in customer service and customer relations.

As a result of the abovementioned complex analyses and data, the systems' Decisions Engine utilizes the metadata catalog and models and generates as a real time process a bespoke aggregated training program for each student that targets the areas of greatest potential impact.

The methods and algorithms used to determine the personalized education programs are based on fuzzy logic and the fuzzy set theory for the primary feedback data, which permits the gradual assessment of the membership of elements in a set and on the Bayesian probability for the progress tracking data, which employs the concept of probability as "a measure of a state of knowledge". These methods are used by the system's Decisions Engine to modulate the common educational program superset into self-adjustable personalized course of study content and experience.

\section{CONCLUSION}

Some of the many advantages of the proposed approach and applied methodology are the ability to offer custom-designed education that fits individual's needs, competence level, experience, aptitude, learning speed, and their persevered strengths and weaknesses on one side and the flexibility of nimble mobile distance education, on the other side.

Insignificant limitations of the system are the decreased ability for group and face-to-face interactions, which, however, are common constraints of the online education. Considering the holistic feedback and assessment as an integral piece of the program of study and the rich multimedia content, this limitation would be significantly reduced.

There are number of possible applications, with the most obvious being the professional, compliance and skills development types of trainings, as well as the various vocational and certification programs. In our case study, the system is going to be implemented for the travel and tourism industry with courses on customer service and customer relations. The travel and tourism industry delivers, in most instances, an intangible product (a service) and therefore the quality and the competitiveness is determined primarily by the competences and quality of the services rendered. 
The online education, as part of the broad effort for sustainable lifestyle and green environment will continue to grow. The need for lifelong education and the desire for convenience will create, said A. Frank Mayadas, director of the Alfred P. Sloan Foundation's grant program for online education, "a tremendously enhanced demand for this kind of education... Online education will be the learning standard within the next 25 years..." (Blumenstyk, et al, 2006).

\section{AUTHOR INFORMATION}

Mr. Lubomir Bojilov, Dipl. Eng., MBA is currently the Director for Information Systems at University of California Santa Barbara (UCSB) where, for over a decade, he's been leading the analysis, architectural design and development of student information systems and technologies. Before this, he was the President and Technical Director for Silicon Delta Corporation, a California-based company that was an emerging provider of mobile software and services. From 1994 to 1998, Mr. Bojilov was the General Manager of Infogroup Bulgaria, Ltd., one of country's leading systems integrators. He began his carrier as a research programmer more than 25 years ago.

Mrs. Jivka Bojilova, MSCS is currently a Systems Architect for Administrative Information Systems at University of California Santa Barbara (UCSB), leading the development of core administrative and financial systems. Before this, Mrs. Bojilova was a Database Integrator for UCSB Marine Science Institute and as a part of an international research team she co-authored publications about Managing Scientific Metadata and participated in the creation of Metacat, a knowledge network for integration of distributed heterogeneous research data. From 1995 to 2000, Mrs. Bojilova has been developing various large information systems for University of California Riverside and Fadata, Ltd. in Bulgaria.

Mrs. Desislava Kachlakeva, MSc Econ. is the Managing Director for DDK Travel (Arroyo Grande, CA) and General Manager of DDK Consulting Services, Ltd. (Sofia, Bulgaria). From 1992 to 2002, Mrs. Kachlakeva worked for Balkantourist AD, Kuehne \& Nagel $\mathrm{GmbH}$, and Transpres Ltd in Bulgaria, where she has gained extensive experience in international tourism, travel administration, and international business. Currently, she is enrolled at the University of Massachusetts' executive MBA program. In addition, she has been specialising in customer relationships and high quality customer services.

Dr. Damian Kachlakev, Ph.D., P.E. has over 25 years of academic experience as a university lecturer and a researcher in U.S. and Europe. He is currently a Professor of Civil Engineering at California Polytechnic State University (San Luis Obispo, CA) and the Director of the National Pool Industry Research Center. Professor Kachlakev is also the General Manager of EuroCompo Ltd, a member of the Board of Directors of the NPC Research Foundation and various standardization committees. From 1987 to 2000, he's been teaching at the Oregon State University and at the University of Architecture, Civil Engineering and Geodesy - Sofia, Bulgaria.

\section{REFERENCES}

1. Blumenstyk G., 2006, The Wired Campus: The Lost Opportunities of Online Education?. The Chronicle of Higher Education. Washington, D.C., USA

2. Carnevale D., 2006 Company's Survey Suggests Strong Growth Potential for Online Education. The Chronicle of Higher Education, Information Technology Volume 53, Issue 13, Page A35

3. Jones M., Berkley C., Bojilova J, \& Schildhauer J. 2001. Managing Scientific Metadata. IEEE Internet Computing. 5 (5): 59-68.

4. $\quad$ Lobsenz R., et al, 2004, Best Practices in Reporting 360-Degree Feedback. viaPeople, Inc. pp. 1-6.

5. Shoikova, E and Denishev, V., 2009, The TENCompetence EPIQ's business demonstrator development, International Journal on Continuous Engineering Education and Life-Long Learning, Vol. 19 